On the Meaning of Sustainable Development: Humanity and Culture in the Age of Gaia and the Singularity

\title{
1) The Age of Sustainable Development
}

We are in the age of sustainable development. This is not because Jefferey Sachs (2015) proclaimed it so. Nor is it because the inhabitants of planet Earth have suddenly transformed their socio-technical existences in such a way as to ensure the long-term survival of humans and other forms of biological life, but rather because, at long last, the agenda of attending to the ways in which the carelessness of the present threatens the possibility of the future has gone mainstream. Sustainable development has become a cultural imperative. International organizations public and private are increasingly touting their advocacy of sustainable development, while nations trot out Green New Deals and companies great and small scramble to become sustainable. Education too has hardly been spared this transformation. Schools of all types are striving to include sustainable development in their curricula, while researchers in the education sciences pump out reams of research on how to do this. The following text is clearly to be situated within this upwelling of interest for sustainable development, though it approaches the issue of sustainable development from a heterodox perspective, looking at the meaning of sustainable development primarily in cultural terms.

The basic question that this paper sets out to answer is simple and commonplace-what is sustainable development? — but the way that we understand this question is anything but typical. Virtually all debates around sustainable development, and all answers to this question, understand it as a question about how to achieve sustainable development. They then answer the question according to one of two dominant understandings of the meaning of this term. On the one hand, there are sustainabilists, i.e. those who understand sustainability in terms of the concept of limits. On the other hand, there are developmentalists, those who place the emphasis upon the idea of development, and the notion of growth. Another way of differentiating these two positions is to note that each holds a different thing to be absolutely scarce. Sustainabilists believe that what is scarce is material. Developmentalists, on the other hand, think that what is scarce is intellectual. It is typical of sustainabilists to insist that there are not enough material 
resources on Earth for the human economy and the human population to continue to grow indefinitely, and so to understand development not as growth but as a tending towards a society well-calibrated to determined material limits. Developmentalists, on the other hand, argue that if we had more knowledge — and generally more technology — we would be able to find and exploit new resources, thus sustaining growth in all of its forms. From an educational point of view, sustainabilists tend to focus on inculcating knowledge of well-defined system limits and fostering a culture of joyous sobriety and restraint, while developmentalists tend to focus on fostering creativity and technical innovation, with an emphasis on building a culture around bold visions and grand collective challenges. Yet our answer to the question, indeed our interpretation of its meaning, is utterly different. We are interested in understanding what it means to us as a culture to ask questions like what it is to develop sustainably, and above all, what it might mean to organize our culture around a concept that solicits two profoundly differing interpretations.

Our interpretation of sustainable development will attribute meaning to "sustainable" and "development" and will also call upon concepts of limits and of scarcity. The starting point of our interpretation is the observation that both of the typical and divergent accounts of the meaning of sustainable development have something in common: they both suffer from what Hans Blumenberg called “insufficient reason" (Blumenberg, 2019, p. 197). Restated somewhat more provocatively, neither of these postures is so sustainable as an argument to make them capable of serving as a solid foundation for the development of a firmly and absolutely grounded vision for future society. This is not because each vision fails to offer guidance and teleological orientation to human activities, but rather because each discourse, when analyzed critically, can never rise above the status of rhetoric, here understood as ungrounded or speculative and hence deficient argumentation. As such, the age of sustainable development — which from our point of view is ultimately that era in which the divergent unity of both of these two discourses becomes a major cultural force - can be characterized not in terms of its lack of material resources or scientific knowledge, but rather by the insufficiency of its reason.

It is not our intention to absurdly claim that this disqualifies all talk of sustainable development to the extent that we should banish it from our current cultural politics. Our suggestion is rather that this insufficiency of reason is already playing a major role in the cultural politics that are 
emerging in the age of sustainable development, and that the fractures of the present will be of particular importance to understanding ourselves when and as we survive the anticipated collapse that has driven towards sustainable development. It is our suggestion that failing to grasp the rational insufficiency of the concept of sustainable development will hinder the ways in which cultures embrace coming transformations, possibly leading to a breakdown in dialogue between sustainabilists and developmentalists. Though the full realization of this threat remains speculative, the following pages offer a historical and conceptual analysis of the fracturing already taking place between the current discourses of sustainabilism and developmentalism, with this fracturing being treated as a symptom of what occurs when we place unwarranted conceptual weight on the idea of sustainable development. What our reading of the present senses of sustainable development shows is that the quest to ground "their" sustainable development has already prompted leading advocates of both sustainabilism and developmentalism to seek ideological support for their visions in two rising and rivaling theological constructions: Gaia and the Singularity. These figures, and the polarization of culture that they herald, are indeed dangerous; particularly in the current context, where the embrace of sustainable development is generally motivated by the sort of irrational enthusiasm inspired by the acknowledgment of climate change as existential risk, and the strong emotions this acknowledgement inspires. As ever, the adherence to theological absolutes hampers dialogue and heightens enmity. It situates two groups who ostensibly want the same thing-sustainable development, a brighter common future - into two opposing camps, with each side regarding the other as spouting incoherent and dangerous non-sense. Yet the threat here is not merely a breakdown in parliamentary procedure. If the Gaians follow Gaia, and the Singularitarians follow the Singluarity, humankind — assuming that it avoids eco-catastrophe — risks not only being riven by differences in opinion, but also to be fractured into two utterly divergent kinds of being.

\section{2) Sustainabilism}

Sustainabilist discourse is built upon a logical truth: that there must be limits to growth within a closed system. Ssutainabilists assume that when we overshoot the limits to growth our society will either decline or collapse. Development for them involves tending the telos of human 
civilization asymptotically towards an accommodation with this limit, via the adoption of some version of what Herman Daly (1977) calls a steady state economy. All of this seems reasonable enough, though an issue arises immediately when we attempt to posit and locate this limit. After all, do we really know the limit to growth? And how can we ever be sure that our limit it the absolute, or right limit?

\section{a) Positing}

The history of sustainabilist discourse is a history of limit paradigms. Carlowitz ((1713) 2009), one of the first to hold a sustainabilist discourse, argued that there was a limit to the number of trees that could be harvested without considerations regarding the "conservation and cultivation" of the forests. Malthus ((1815) 1992 ), insisted that the limit that mattered was the quantity of agricultural land. For Jevons (1866), the limit paradigm was the amount of extractable coal in England. Within the current understanding of sustainable development, the limit paradigm is the Earth itself. The formalization of this limit paradigm in sustainabilist discourse can be traced back to the publication of The Limits to Growth (Meadows, Meadows, Randers, \& Behrens, 1972). The authors of Limits showed that global economic development would ultimately be constrained by planetary limits and argued that if we did not respect these limits our society would collapse. This limit paradigm was taken over in the first political pronouncements regarding sustainable development. The 1987 Brundtland Report begins with an evocation of how humankind first discovered the Earth - and its limits - from outer space, describing the discovery of the planetary limits as a veritable Copernican revolution in the human understanding of our own development:

In the middle of the 20th century, we saw our planet from space for the first time.

Historians may eventually find that this vision had a greater impact on thought than did the Copernican revolution of the 16th century, which upset the human self-image by revealing that the Earth is not the centre of the universe. From space, we see a small and fragile ball dominated not by human activity and edifice but by a pattern of clouds, oceans, greenery, and soils. Humanity's inability to fit its activities into that pattern is changing planetary systems, fundamentally. Many such changes are accompanied by life-threatening hazards. 
This new reality, from which there is no escape, must be recognized - and managed.

(Brundtland, Khalid, Agnelli, Al-Athel, \& Chidzero, 1987)

Needless to say, this limit paradigm remains dominant: it is this this paradigm that underwrites the current wave of Anthropocene discourse as well as the nine planetary boundaries popularized by the Stockholm Resilience Center.

\section{b) Defending}

The problem with all of the limits posited by sustainabilists, however, is that they are speculations. That is not to say that there are no planetary or other limits, but to know these limits in scientific terms would involve testing them through experience by intentionally overstepping them and then measuring the consequences. Yet since this knowledge would be valueless - humankind would potentially die in the quest of this knowledge - the limits posited by sustainabilists are not only without ultimate validation, they are precisely intended to keep us from seeking such validation, to the extent that the point in positing these limits is to keep us from overstepping them. Obviously, this has hardly stopped advocates of sustainabilism from seeking out examples which support the supposition that development must be bounded by limits, and to seek data encourage us to believe that our limit paradigm is the correct or absolute limit paradigm. Vaclav Smil (2019), for example, recently published a monumental study documenting, based on the best recent scientific evidence, the limits to growth of everything from microbes to megacities. Sustainabilists such as Jared Diamond (2004) have also combed the past in search of examples aimed at illustrating the collapses that have ensued when civilizations have overstepped and ignored the biophysical limits to their growth. Yet publications of this sort, if they bolster the claim that we ought to attend to the limits of growth, in no way clarify the fundamental question of whether our limits are the absolute limits. This question matters, since the limits that we accept ultimately determine how much we as a species can hope for.

At least since Gerard O'Neill's publication of The High Frontier (1977), critics of the current paradigm have been pointing out the irrationality of the planetary limit paradigm. As O'Neill argued, it was at least in principle possible for humankind to move out into space, and when there, continuing "exponential growth" would be possible, thanks to virtually unlimited access to 
energy, lands, and materials (all "available without stealing, or killing, or polluting" (loc.594)). Sustainabilist thought leaders like Garret Hardin (1993) and Mike Berners Lee (2019) have long responded by claiming that expansion into space was impossible. In retrospect, these demonstrations have proven far from convincing: a robotic space economy is booming, and the drive to gain access to space resources and to pave the way to an eventual settlement of near space, is currently a major developmentalist prerogative, pursued both by national governments including the US, China, India, and the UAE, as well as by individual investors, including Jeff Bezos, Elon Musk, and Larry Page. Yet whether or not space expansion offers a legitimate new paradigm for growth in a way does not matter, since the extensive limits to the planet are not the only ones in question. Developmentalists have also increasingly embraced a discourse suggesting that even if we are stuck on Earth, the limits of the Earth pose no meaningful limit. Nanotechnology pioneer Eric Drexler (2013) has argued (quoting physicist Richard Feynman) that "there is plenty of space at the bottom," by which he means that there is plenty of room for progress at a nano-scale. In other words, when seen at an atomic level, even an ordinary object seems to contain an almost impossible abundance and room for growth, with the Earth itself being a kind of multiverse populated by virtually endless multitudes of miniature cosmoi. Drawing on data gathered over the last fifty years, Andrew McAffee (2019) has shown that thanks to technologies enabled by nanoscale miniaturization - computers, the Internet, and other digital technologies — we are going through an era of dematerialized growth in which the substitution of "bits for atoms," has allowed us to "consume more and more while taking less and less from the planet" (3). The sustainablist Vaclav Smil has rebuffed this claim, insisting that "arguments about the impressive miniaturization (and hence dematerialization) of modern electronics are based on faulty assumptions. Smartphones may be small and light but their energy and material footprints are surprisingly large" (Smil, 2019, p. 500). But if Smil wins the point, it remains arguable whether he wins the war, since it is extremely difficult to sustain that the imaginable limits on dematerialized growth - the markets of purely virtual goods and services - are identical to the limits of the material equivalents of those same services, and so require the same sorts of transformations of our mode of existence.

\section{c) Sacralizing}


Adding to the difficulty of defending any developmental limit paradigm is the fact that in practice almost all limits posited by sustainabilists are intentionally conservative. From the point of view of an ethics built upon the principle of prevention that generally prevails in sustainabilism this makes sense, but it does create problems regarding the justification of the sustainabilist picture of reality. For example, it has been argued that we have currently overstepped five of the nine planetary boundaries ('limits') set forth by the Stockholm Resilience Center (Rockstom \& Klum, 2015). Yet the problem with this observation is it reveals the fact that these supposed boundaries precisely are not boundaries in the absolute sense of the termsince real, absolute boundaries would be incapable of being transgressed without disaster. In consequence, sustainabilist discourse has recourse to a secondary boundary notion: "resiliency" (Rockstom \& Klum, 2015, p. 70). As used by the theorists of the Stockholm center, resiliency is employed to posit a limit beyond the limits, the limit to resiliency, a kind of secondary or real limit that is supposed to manifest itself in the course of the prolonged or extreme violation of the initially posited limit. Yet the problem with relying on the limits of resiliency as a support for our limits discourse this tends to undermine the very idea of the limit itself as absolute or real. This in turn encourages developmentalist accounts, which tend to look upon limit paradigms as human constructs expressive not of real natural limits, but realisms about the world expressive of the limits of the human imagination. In any case, and in order to support the idea that their limits, despite their limitations, ought to be respected and treated as absolute, many sustainabilists are now looking to theology to sacralize their posited limits.

Perhaps the most well-known of these theological supplements to sustainabilist reason is the figure of Gaia. Gaia is generally not presented as really being a goddess, and her adherents tend to deny that belief in her constitutes a religion (Bruno Latour claims that Gaia is perhaps "the least religious entity ever produced by occidental science" insisting that she is "totally secular" and even "mundane or earthly." (2015, p. loc. 2294) She is, as Bruce Clarke explains, "a selfgenerating, self-maintaining planetary constellation emerging from the interactions of living and nonliving components - systems and structures, embodying their integrated intermodulations" (2019, p. 11) Yet if Gaia is not a religious figure like the Christian God, but something like a figuration of the complex Earth systems, she does incarnate a reason for believing that the planetary limit paradigm is the right or ultimate limit paradigm. Indeed, given that Gaia is and 
acts as an Earth goddess, this makes the planetary limit a sacred and hence ultimate limit whose true guardian is not the discursive constructions of the sustainabilists, but the planetary wrath of the Gaian system in its punishment of those who do not respect the limit. As Latour argues, we see Gaia through her decisions - her judgements and character emerge in the court of evolutionary history, over which she is "the final judge" (p. 6080). Latour quite reasonably advocates for Gaia as he sees in this figure a way of generating collective action around a common belief, but a secondary usage of the Gaia figure is in the service of rather poor prosustainabilist arguments which in their turn give energy to the enemies of sustainabilism. Clarke, for example, has argued (following Lynne Margoulis) that the reason why O'Neill and Bezos' plans to build space cities will fail comes down to Gaia - that we humans don't, and won't ever, know enough to reproduce Gaia, i.e. living systems in space (2019, p. 138). This argument may be true, but the idea that Gaia plays any role in space ecosystems engineering is laughable to non-believers. Indeed, rather than offering a real scientific argument, the evocation of Gaia disturbingly functions not as a way forwards towards fostering a collective engagement in building a sustainable future (how Gaia is envisioned in Latour), but rather as motive for disregarding sustainabilist insights and concerns as rooted in nothing but fantasy and superstition.

\section{3) Developmentalism}

Developmentalist discourse begins with a paradoxical or impossible claim: infinite growth is possible within a bounded system. But if this claim seems radical, the developmentalist position is itself anything but radical. The project of growth has long been the norm within capitalist nations. As such, developmentalists tend to defend the feasibility of their project with recourse to historical examples, often generated using Elkington's triple bottom line approach, which document that the impossible is possible, that it is feasible to create new products that make money while at the same time generating social and environmental well-being. That said, examples of this type are often unconvincing when presented in terms of the current planetary limit paradigm. They mark trends towards respecting limits, but they offer little to those that might doubt the irreconcilability of growth within limits. For example, electric cars, which are currently proposed as one of the key "solutions" to climate change, self-evidently reduce 
planetary impact compared to Co2 emitting gasoline cars (and so balance on the triple bottom line), but scaling up their production self-evidently implies other issues with respect to the upstream availability of resources for building batteries, the mid-life need for electricity to charge motors, and downstream issues associated with waste disposal and valorization. Because of this, in the following we will focus on a more radical but also philosophically more consistent version of developmentalism, one that argues that unlimited growth is possible because our current limit paradigm is not the ultimate or absolute limit paradigm, and that the future will thus be characterized by abundance, not by scarcity. Developmentalists of this sort argue that innovations and the expansion of scientific knowledge have banished all past limit paradigms to the dustbin of history, a fate that they confidently anticipate will extend to the planetary paradigm as well. As Singularity University founder Peter Diamandis and his co-author Steven Kotler argue, it is the nature of technology to make the "once scarce now abundant" (2012, p. 4). Yet to break out of our current paradigm demands taking risks. It requires testing the limits of what seems to be reality and demands relying on an ungroundable belief in the infinite power and unjustifiable efficacy of human creativity. In the quest to ground these beliefs, developmentalism fetishizes an immaterial spirit which it imagines will ensure the transcendence of all limits, and so too slips over into a discourse rooted in belief and fantasy.

\section{a) Transgressions}

Developmentalists both admit and don't admit the limits to growth. They recognize that within the currently dominant resource paradigm - the planet seen at a macro-scale - the total number of resources seems limited. But the most optimistic developmentalists nevertheless believe that this seeming is an illusion. They can offer plenty of reasons why we should believe them. Jevons, Malthus, and the authors of the Limits to Growth were all wrong about the specific limit paradigms that they diagnosed, with their errors in every case deriving from their failure to anticipate the ways in which innovation would alter resource demands, extending and altering our picture of the world. In other words, even if it remains true that both the amount of agricultural land in England (Malthus) and the amount of coal contained in England (Jevons) are finite, these facts have in no way halted the growth of either the English population or economy. Technological advances made these limit paradigms irrelevant. Jevons did not anticipate that the 
economy could use other energy sources than coal, and he likewise did not anticipate that it would soon be cheaper to merely design products in England and have them manufactured and shipped in from elsewhere. The lesson that the developmentalists draw from these examples is not that there are no absolute limits to growth, but that whatever these limits are, they are likely not the ones that we currently imagine. This overall vision is summed up nicely by Earl Ellis, who argues that it has never been "planetary boundaries" and "classic biophysical limits" that have constrained human growth, but the limits of our technological and collaborative systems, what he calls "human system boundaries." Judging by the current rate of technological progress - which many of the most optimistic allege is exponential after the image of Moore's law-Ellis argues that there is no sign of the growth in human system boundary expansion slowing down - and that "as food and other basic resources are concerned, we remain far from any physically determined limits to the growth and sustenance of our populations" (Elis, 2011, p. loc. 680).

Developmentalists tend to argue that there are at least four paths towards the acquisition of new resources and abundant growth. The first of these is expansive sustainability. This involves the transgression of the limits of the planet in order to obtain access to space resources. Expansive sustainability is in many ways the most traditional version of developmentalism, since it is the transposition of the much older developmental logic of globalization into an extra-global context. Advocates of this view, who include Jeff Bezos, Elon Musk, and many others, highlight the current progress being made towards decreasing the costs of access to space, and they predict that we will soon become a post-planetary species, enjoying the riches of space in an era of what Joseph Pelton (2017) calls "astral abundance." The second developmental threshold is the nanofrontier. Nanotechnology is again a fairly traditional developmental conception, as ideologies of progress have always focused on efficiency gains. Even though nano-scale engineering is itself new, the pursuit of "increased capacity and reduced production costs" (Drexler, 2013, p. 222) that is aims to achieve is wholly traditional. Indeed, the only difference between nano-tech efficiency and traditional efficiency is merely one of scale: nano-tech "growth" happens at increasingly small scales, and so the growth of nanotech implies the shrinkage of materials usage. A third way forwards is glimpsed in "dematerialization," or the opening of cyberspace. Simply put, the hope here is that we can produce and consume virtual and not real objects, and so 
vastly expand the available range of goods and services with only a minimal and largely decorrelated expansion of consumed material resources. A final threshold is the neuro-frontier. In essence, almost everyone agrees that if human civilization is unsustainable, it is not because the planet is too small, but because human beings have bad habits. They drive when they should walk. They eat meat as opposed to vegetable proteins. They choose real products as opposed to their lower environmental cost virtual alternatives. Neuro innovations seek to use technologyfor example things like selective algorithms, nudges and gamification- to tweak what MIT professor Alex Pentland (2014) calls the "social physics" of contemporary societies. Simply put, it is wholly realistic to imagine that we can engineer future generations that are more sustainable because they have been programmed to consume more and more of things that are less and less materially real. The most optimistic advocates of development claim that we are not only far from the limits to growth, but that we are on the verge of crossing a limit that Ray Kurtzweil calls the "singularity," the moment when "machine intelligence will surpass human intelligence," and that this will open up a whole series of new avenues for sustainable innovation and development, ultimately issuing in a post-scarcity era characterized by "the merger of biological and nonbiological intelligence, immortal software-based humans, and ultra-high levels of intelligence that expand outward in the universe at the speed of light" (Kurzweil, 2008, p. 1).

\section{b) Raptures and Reality}

That future sounds like science fiction. It is thus hardly surprising that some developmentalists, for example, Ross Thornley, the man responsible for the advertising campaign used to popularize the 17 SDG's, claim that "the future we often see in Science Fiction movies, is far closer than you think." (2019, p. 18) This embrace of SF as reality as opposed to fiction is closely bound up in the rejection of our current limit paradigm as mere seeming. After all, believing that infinite growth is possible in a finite system is a-priori absurd, and so belief that the unreal is real seems not a bug but a feature of this ideology. Indeed, the only way of coherently sustaining a belief that infinite growth is possible despite the manifest limits of the Earth is to precisely claim that what seems true - that our world is limited — is but an illusion. 
One of the great discoveries of the Enlightenment rationality is just how simple it is to demonstrate the fraudulence and the illusions in other people's pictures of reality.

Developmentalists such as Steven Pinker (2018) draw on this enlightenment rhetoric to bolster confidence in human capacities, and in particular the capacity for creativity and technological innovation, since these are understood as the powers needed to bring forth new realities. Rebecca Henderson, for example, a Harvard Business School professor, insists that "humans are infinitely resourceful," arguing that we have the "technology and the resources to fix the problems that we face” (2020, pp. 11-12). Serial entrepreneur and Singularity University faculty member Naveen Jain is even more hyperbolic when it comes to the assessment of human capacity. As he writes: "People often say the sky is the limit. The sky is not the limit. There is no such limit. It is an artificial boundary. Imagination is our only limit. If we can imagine something then we can accomplish it" (2018, p. 54)

Yet if the sky is not the real limit, developmentalists are quite clear about the fact that aiming to transcend the sky, striving after what Jain, Thornley, Diamandis and others call "moonshots" or "loon shots" is difficult. This is because most of us don't believe that our reality is not real. Indeed, virtually the whole of our experience habituates us to seeing the sky as the limit, since we are not, as a point of fact, birds. To counter these fears, developmentalists are fond of saying things like "Good ideas are always crazy until they're not" (the quote is from Google founder Larry Page). ${ }^{1}$ In order to overcome our anxiety when taking seemingly irrational risks, developmentalists encourage us to do things such as intentionally cultivating alternate mind states, since these have been found to be a key to unlocking outside of the box thinking, an activity that Kotler and Wheal (2017, p. 2019) analogize to learning how to sound the Elusinian mysteries, and learning to imitate Prometheus in initiating a technology-empowered rebellion against the established order of the cosmos. Others are encouraging us to engage intentionally in seemingly fatalistic attempts to transcend the limits of the possible, arguing that we should not be afraid of failure, and that the best mode of continuing to move forwards is not to observe the principle of precaution, but rather what Kevin Kelly calls the "proactive principle," "to

${ }^{1}$ Quote is from Ashlee Vance's (2015, p. 354) biography of Elon Musk. 
proactively engage and test and try the technology out in the present" (2011, p. 260). Or, as Diamandis and Kotler re-phrase it: "Fail early, fail often, fail forward!" (2012, p. 114).

\section{c) The Spirit of Development}

But what is the justification for all of this risk taking, which unquestionably seems aimed at discouraging us from acting in a way that seems measured, precautious, and reasonable? Naveen Jain answers this question perfectly when he claims that "sustainability isn't sustainable," justifying this paradoxical claim by explaining that the conservatism towards limits that is defended by the sustainabilists constitutes the "single greatest threat to the survival of humanity," since rather than encouraging bold risk taking and growth as a response to "managing our dwindling resources," it accepts the sacrifice of development, and so ensures scarcity's continuing "dominance in the world" (2018, pp. 10-11). Yet if sustainability isn't sustainable, is radical risk taking more sustainable? Is there any reason to believe that at some point in time humankind will not run out of resources - or even creative ideas - and then regret not simply settling down and learning to live in happy sobriety according to some reasonable limit paradigm? Given the existential uncertainty generated by these questions, one would expect developmentalists to seek support in fantasy constructions, which of course they do.

Nobel prize-winning economist William Nordhaus and Michael Schellenberger, for example, have argued that having faith in human development requires "a new secular theology," which they call "modernization theology." (2011, p. 204) John Elkington, the economist behind the famous triple bottom line concept so widely employed by corporations today, has argued that we ought to regard each "statistically improbable" event of an innovation that squares the circle of growth within limits as a "green swan," which he describes as a kind of "miracle" that "invites us to step into a larger world in which new things are possible" (2020, p. 24). Yet even if the term miracle here might seem secular-after all, we know that it is humankind, or at least some magical communion of man and nature, that made these "green swans"- the clearly religious connotation of the word miracle is justified insofar as the point of calling green swans miracles is that they inspire faith and belief that infinite growth really is possible. After all, even if we admit 
the reality of outerspace, nanospace, cyberspace, and inner space, all of the alternative paradigms to be conquered through innovation, we rather quickly realize that these paradigms are extremely limited with respect to the alternatives that they actually seem to provide for a future humanity. Human bodies are ill-adapted to life in outer space and bringing resources back from space seems impossible both due to the Earth's gravity well and to the potential waste problems that such practices would generate. Similarly, it could only be an alter-bodied humankind that might live at nano-scale, while living in cyberspace will require at least partial dis-embodiment. Sustainably mastering our collective inner space via technology-enabled mass manipulation seems utterly possible, but as Morizov (2014) and Zuboff (2019) have made clear, it is probably anything but desirable, since what it risks sacrificing is not our human bodies, but rather that perhaps most valued aspect of our humanity: our free wills. Simply put, understanding how development can make us sustainable remains incomprehensible to us as human beings, and believing that it will make sense to some future human being is a leap of faith in the power of some future human being that will not, in essential ways, even be what we would normally consider human. Indeed, pushed to its limit, the humanity for whom infinite growth is possible is pure spirit. To re-tweet Elon Musk, the aim of his space expansion endeavors is to "make life multiplanetary" and to protect "the light of consciousness." (2020) Not humanity: consciousness. Yet consciousness and pure spirit are not empirical or material things, and the existence of such a consciousness that can float forth out of our bodies and accomplish what we currently cannotthe singularity - is something that only exists as an object of belief and fantasy. It is the sovereign figure in a religion in which the material darkness of the human body and the body of the Earth are evil, while the pure ether of consciousness and spirit is the ultimate and only good. Needless to say, anyone arguing that we can destroy the Earth and our bodies because our immortal spirits will be saved on a hard drive located in outer space will have a hard time convincing anyone who is not likewise a Singularitarian.

\section{4) The Great Divide}

At the extremes - and that is also to say at their points of utmost logical coherence-both the discourse of sustainabilism and developmentalism lapse into theology or spiritualism. In itself this is perhaps no issue, the turn towards figures like Gaia or the Singularity may well perform a 
key role in binding together networks of actors engaged in the name of developing sustainably. It may also be inevitable: readers who are familiar with Kant's Critique of Pure Reason (1998 (1787)) will have noted the ways in which the above text is indebted to his discussion of the "antinomies of pure reason," in essence, the set of undecidable questions and ungrounded speculative answers that emerge when one follows the logical extrapolation of the products of the understanding out beyond the field of any possible experience. Arguably, it is true that most people who care about sustainable development will not do so in a rationally rigorous mannerin essence they won't seek out an ultimate reason or ground justifying their interpretation of sustainable development, and so they won't be tempted to embrace either Gaia or the Singularity. That said, it is also a common human desire, and not a mere peculiarity of the philosopher, to seek justification in absolutes.

Hans Blumenberg, from whom I have borrowed the notion of insufficient reason, once argued that insufficient reason was "the axiom of all rhetoric," noting that the rhetorical situation was the "correlate of an anthropology of a creature who is deficient in essential respects" (2019, p. 198). There seems to me to be something rather profound about this observation with respect to the cultural condition in the age of sustainable development. In the end, what separates the two interpretations of the meaning of sustainable development are differing images of what might be called a human future. Yet these two humanities differ radically, as the developmental trajectories that they wish to sustain are utterly different. The believers in Gaia envision a future humankind that will be, to an ever-increasing degree, wedded to the Earth. These Earthlings will cultivate a belief in the planet and its chthonic powers as supreme deciders, and in so doing they will renounce many of the key features of the modern discursive construction that is the human. Stated more precisely, these Earthlings will become post-human in precisely the sense that this term is used by Rosi Braidotti, they will be a form of life that rejects the "universalizing powers of self-reflexive reason" that are characteristic of the anthropology of the modern age, embracing rather a sense of themselves as "relational subject[s] constituted in and by multiplicity," (2013, p. 49) with the name of that constitutive multiplicity being Gaia. The future humankind envisioned by the advocates of developmentalism will also be post-human, but in a wholly other sense. It will retain the universalizing powers of self-reflexive reason, it will still be capable of "inventing and wandering," to adapt two terms expressive of the essence of the human according to 
Amazon.com and Blue Origin founder Jeff Bezos (2021), and fully characteristic of the anthropology of the modern age, or at least that of the homo oeconomicus. Yet this developmentalist subject will also be, to borrow a phrase from cyberpunk master William Gibson, "no longer even remotely human" (1986, p. 16). If the future species born of developmentalism may not necessarily be a brain in a vat living as a ghost in a machine - as is the no longer even remotely human character in Gibson's Count Zero - the aliens worshippers of the Singularity may well be beings of augmented mind and body, inhabitants not of Earth but island colonies at L5. Speculatively, then, it seems that what is at stake in the age of sustainable development is not merely the extinction the species at the hands of Earthly forces but also the death of humanity at the hands of those who aim to preserve us from collapse. In other words, part of the challenge of the age of sustainability is not merely the survival of the species, but its survival as a species. There are many ways in which we could think about the meaning of the loss of humanity. In cultural terms, however, I might suggest that this may transpire in the form of a loss of common ground. Stanley Cavell, writing of how and why we understand what each other have to say, argues the very basis of communication is the "routes of interest and feeling, modes of response, senses of humor and of significance and of fulfillment, of what is outrageous, of what is similar to what else, what a rebuke, what forgiveness, of when an utterance is an assertion, when an appeal, when an explanation" (2015, p. 52). These avenues of a shared sense of being in the world, and our shared sense of what matters, may well be both what we share and how we identify our common humanity. It seems open to question whether Earthings and Singulatarians will indeed have these shared modes and moods, especially once they develop their projects for sustaining the future. But that is obviously speculation. What is sure, however, is that embracing sustainable development as will have radical, and divisive effects on our culture, even - and perhaps especially — if we manage to durably sustain our material lives in this time of climate change.

\section{Works Cited}

Berners Lee, M. (2019). There Is No Planet B: A Handbookfor the Make or Break Years. New York: Cambridge University Press.

Bezos, J. (2021). Invent and Wander (Kindle ed.). Boston MA: Harvard Business Press. 
Blumenberg, H. (2019). History, Metaphors, and Fables. (H. Bajohr, F. Fuchs, \& J. P. Kroll, Eds.) Ithaca: Cornell University Press.

Braidotti, R. (2013). The Posthuman. London: Polity.

Brundtland, G. H., Khalid, M., Agnelli, S., Al-Athel, S., \& Chidzero, B. J. (1987). Our Common Future. New York.

Carlowitz, H. C. ((1713) 2009). Sylvicultura oeconomica. (P. Warde, Trans.) Leipzig: Johann Freidrich Braun.

Cavell, S. (2015). Must We Mean What We Say? London: Cambridge University Press.

Clarke, B. (2019). Gaian Systems. Minneapolis: University of Minnesota Press.

Daly, H. (1977). The Steady State Economics. New York: Island Press.

Diamandis, P., \& Kotler, S. (2012). Abundance: The Future is Better than You Think. New York: Free Press.

Diamond, J. (2004). Collapse: How Societies Choose to Fail or Succeed. New York: Viking.

Drexler, E. (2013). Radical Abundance: How a Revolution in Nanotechnology will Change Civilization. New York: Public Affairs.

Elis, E. (2011). The Planet of No Return: Human Resilience on an Artificial Earth. In N. Schellenberger (Ed.), Love your Monsters: postenvironmentalism and the anthropocene. New York: Breakthrough Institute.

Elkington, J. (2020). Green Swans: The Coming Boom in Regenerative Capitalism. New York: Fast Company.

Gibson, W. (1986). Count Zero. New York: Penguin.

Hardin, G. (1993). Living Within Limits. New York: Oxford University Press.

Henderson, R. (2020). Re-Imagining Capitalism in a World on Fire. New York : Public Affairs. Jain, N. (2018). Moonshots: Creating a World of Abundance. New York: Moonshots Press.

Jevons, W. (1866). he Coal Question; An Inquiry Concerning the Progress of the Nation, and the Probable Exhaustion of Our Coal Mines. London: McMillan.

Kant, I. (1998 (1787)). Kritik der reinen Vernuft. Berlin: Meiner Verlag.

Kelly, K. (2011). What Technology Wants. New York: Penguin.

Kurzweil, R. (2008). The Singularity is Near. New York: Penguin .

Latour, B. (2015). Face à Gaia: Huit conférences sur le nouveau régime climatique. Paris: La découverte.

Malthus, T. ((1815) 1992 ). An Essay on the Principle of Population. New York: Cambridge University Press.

McAffee, A. (2019). More From Less. New York: Scribner.

Meadows, D., Meadows, D., Randers, J., \& Behrens, W. (1972). The Limits to Growth. New York: Universe Books.

Morizov, E. (2014). To Save Everything, Click Here: The Folly of Technological Solutionism . New York: Public Affairs.

Musk, E. (2020, June 1). Elon Musk Status. Retrieved from Twitter.com: https://twitter.com/elonmusk/status/1267531196751323144?lang=en

O'Neill, G. (1977). The High Frontier. New York : William Morrow.

Pelton, J. (2017). The New Gold Rush! The riches of space beckon. Cham, Switzerland: Springer. Pentland, A. (2014). Social Physics. New York: Random House.

Pinker, S. (2018). Enlightenment Now: The Case for Reason, Science, Humanism, and Progress. New York: Penguin. 
Rockstom, J., \& Klum, M. (2015). Big World Small Planet: Abundance Within Planetary Boundaries. New Haven: Yale University Press.

Sachs, J. (2015). The Age of Sustainable Development. New York: Columbia University Press.

Schellenberger, M., \& Nordhaus, T. (2011). Evolve: The Case for Modernization as the Road to Salvation. In Schellenberger, \& Nordhaus (Eds.), Love Your Monsters:

Postenvironmentalism and the Anthropocene. New York: Breakthrough Institute.

Smil, V. (2019). Growth: From Micro-Organisms to Mega Cities. Cambridge MA: MIT Press.

Thornley, R. (2019). Moonshot Innovation: How You Can Positively Benefit a Billion People. New York: Create Space.

Vance, A. (2015). Elon Musk: Tesla, Sapce X, and the Quest for a Fantastic Future. New York: Harper Collins.

Wheal, J., \& Kotler, S. (2017). Stealing Fire: How Silicon Valley, the Navy SEALs, and Maverick Scientists Are Revolutionizing the Way We Live and Work. New York: Dey Street Books.

Zuboff, S. (2019). The Age of Surveillance Capitalism. New York: Public Affairs. 